Research Article

\title{
Prevalence and Associated Factors of Thinness among Adolescent Students in Finote Selam Town, Northwest Ethiopia
}

\author{
Damitie Kebede Mengesha ${ }^{(D)},{ }^{1,2}$ Reddy P. C. J. Prasad, ${ }^{1}$ and Degnet Teferi Asres ${ }^{1}$ \\ ${ }^{1}$ Faculty of Chemical and Food Engineering, Bahir Dar Institute of Technology, Bahir Dar University, P. O. Box 79, \\ Bahir Dar, Ethiopia \\ ${ }^{2}$ College of Agriculture and Environmental Sciences, Bahir Dar University, P. O. Box 5501, Bahir Dar, Ethiopia
}

Correspondence should be addressed to Damitie Kebede Mengesha; dakebede10@gmail.com

Received 29 January 2020; Revised 16 March 2020; Accepted 19 May 2020; Published 2 June 2020

Academic Editor: Adriano Sfriso

Copyright (c) 2020 Damitie Kebede Mengesha et al. This is an open access article distributed under the Creative Commons Attribution License, which permits unrestricted use, distribution, and reproduction in any medium, provided the original work is properly cited.

\begin{abstract}
Even if adolescence is a window of opportunity to break the intergenerational cycle of malnutrition, adolescents are the neglected age groups. Hence, information regarding the nutritional status of adolescents is lacking, making creating and implementing intervention programs difficult. This study aimed to assess the prevalence and determinants of thinness among school adolescents in Finote Selam Town, Northwest Ethiopia. A school-based cross-sectional study among adolescent students aged 10-19 in public primary and secondary schools was carried out in Finote Selam Town from February 05 to March 27, 2018. Stratified and simple random sampling techniques were employed to select study subjects. A total of 397 adolescent students were included in the study. Pretested structured questionnaires were used to collect the data. Data were entered using Epi Info version 7 and analyzed using SPSS version 20 and WHO AnthroPlus software. A multivariable binary logistic regression analysis was employed to identify factors associated with thinness. Crude and adjusted odds ratios with 95\% level significance were used to measure the strength of association, and statistical significance was declared at $p$ value less than 0.05 . The prevalence of thinness among adolescents was $14.9 \%$. Early adolescent stage $(\mathrm{AOR}=4.81 ; 95 \% \mathrm{CI}: 1.23,18.51)$, being male adolescent students $(\mathrm{AOR}=2.33 ; 95 \% \mathrm{CI}: 1.60,3.40)$, having less than 1000 birr family monthly income $(\mathrm{AOR}=6.54 ; 95 \% \mathrm{CI}: 3: 82,14.89$ ), having 1000-2000 birr family monthly income $(\mathrm{AOR}=3.47 ; 95 \% \mathrm{CI}: 1.15,7.45)$, and using well water $(\mathrm{AOR}=3.82 ; 95 \% \mathrm{CI}: 1.46,10.04)$ were significantly associated with thinness at $95 \%$ confidence interval. The study revealed that prevalence of thinness was high in the study area. Sex, place of residence, and family monthly income were found to be important factors associated with thinness among the respondents.
\end{abstract}

\section{Introduction}

Both the UN and WHO define adolescence as a segment of population group age from 10 to 19 years old; it is a transition period from childhood to adulthood and has intense physical, psychosocial, and cognitive development [1]. During this period, the final growth spurt occurs; particularly, early adolescence after the first year of life is the critical period of rapid physical growth and changes in body composition, physiology, and endocrine [2]. Up to $45 \%$ of skeletal growth takes place, and 15 to $25 \%$ of adult height is achieved during adolescence; during the growth spurt of adolescence, up to $37 \%$ of total bone mass may be accumulated [3]. Regarding body composition change, girls begin to store fat around the breast, hips, and upper arm but boys start losing fat and develop muscle [4].

The adolescence period is a window of opportunity for human beings because there is possibility of little catch-up growth [5], and it is a time of changing lifestyles and food habit; changes affect both nutrient needs and intake, so it is an opportunity to shape this new behavior adoption [6]. Our world is a home to 1.8 billion (24.66\%) young people between the ages of 10 and 24 , and the youth population is growing fastest in the poorest nations; currently, adolescents make up roughly $20 \%$ of the global population [7]. In developing countries, adolescents have an even higher $85 \%$ demographic weight, for instance, roughly 26\% in Salvador, compared to $14 \%$ in the USA [8]. Similarly, in Ethiopia, 
children and adolescents constitute about $48 \%$ of Ethiopian population, and about $25 \%$ of the Ethiopian populations are adolescents, but studies among this age group were insufficient [9].

Different researchers conducted a study on thinness among school adolescents in different parts of the country. The prevalence of thinness varies across different regions of Ethiopia. The prevalence of thinness among adolescent girls was $21.6 \%, 28 \%, 21.4 \%$, and $14.8 \%$ in studies conducted in Babille District [10], Bedlle [11], Adwa [12], and Arsi Zone [13]. The overall prevalence of thinness among adolescent school girls in Lay Guyint Woreda, Northwest Ethiopia, was $29.0 \%$ [14]. The prevalence of thinness among adolescent school girls in Adwa Town, North Ethiopia, was 21.4\% [12]. The overall prevalence of thinness among school-going adolescents in Mekelle City, Northern Ethiopia, was 37.8\% [15]. The prevalence of thinness among adolescents in Wukro, Northern Ethiopia, was 26.1\% [16]. However, there was no any study report on thinness in the study area. This study would serve as a baseline for further study and be important for designing intervention and a guide for policymakers and development planners. This study was mainly focused to assess the prevalence and explore determinants of thinness among school adolescents in Finote Selam Town, Northwest Ethiopia.

\section{Methods}

2.1. Study Design and Area. The study design was a schoolbased, cross-sectional study among adolescent students aged $10-19$ in public primary and secondary schools. The study was carried out from February 05 to March 27, 2018. This study was conducted in Finote Selam Town which is located $389 \mathrm{~km}$ northwest of Addis Ababa and $176 \mathrm{~km}$ southeast from Bahir Dar, the city of Amhara Region. Finote Selam town administration has been established to be the main town of West Gojjam Zone since 2004 E.C. The total population size of the town according to 2007 census report was 25913 (13, 035 males and 12, 878 females). The town is situated at an altitude ranging from 1500-2300 meters above sea level and has an area coverage of 116,954 ha. The area receives an average annual rainfall of $1250 \mathrm{~mm}$. The minimum and maximum daily temperatures of the area are 14 and $32^{\circ} \mathrm{C}$, respectively. It is bordered on the north by Sekela and Quarit, on the south by Dega Damot and Burie, on the east by Deg damot and Dembecha, and on the west by Burie. There are six primary schools, one high school, one preparatory school, and five colleges in Finote Selam Town. The total number of students from grade 5-12 was 12,323 [17].

2.2. Source and Study Population. All adolescent students (10-19) in Finote Selam town schools were the source population. Randomly selected adolescent students (10-19) in Finote Selam town schools were study population.

2.3. Sample Size and Sampling Procedure. The minimum sample size required was calculated using single proportion formula. The proportion of thinness among school-going adolescents of Mekelle City, Northern Ethiopia, was 37.8\% [18] at a 95\% confidence level, 5\% margin of error adding $10 \%$ as contingency for nonresponse rate:

$$
n=\left(\frac{z}{d}\right)^{2} x P(1-p)
$$

where $n=$ sample size, $Z=Z$ score at $95 \% \quad C I=1.96$, $p=37.8 \%$, and $d=$ marginal error $=105$ :

$$
\begin{aligned}
n & =\frac{(1.96)^{2} * 0.378(1-0.378)}{(0.05)^{2}} \\
& =\frac{3.8416 * 0.378 * 0.622}{(0.05)^{2}} \\
& =361
\end{aligned}
$$

By adding $10 \%$ nonresponse rate, the minimum sample size required to estimate the prevalence of thinness and its associated factors among adolescent students was $361+10 \%$ $(361+36)=397$.

To obtain the sample, stratified random sampling technique was used. The schools were stratified into primary schools, junior schools, high school, and preparatory school. Three primary schools, namely, Bata, Bakel, and Efrata, and three junior schools, namely, Edgetber, Bata, and Bakel, were selected using simple random sampling from six primary schools and six junior schools, respectively, whereas a high school, namely, Finote Selam Secondary School, and a preparatory school, namely, Damot Preparatory School, were selected purposively since one high school and one preparatory school were present in Finote Selam Town. The total sample size was distributed proportionally to the schools. The sampling frame was students' identification number in their respective school. Numbers of students to be included in the study were determined by a simple random sampling method (Figure 1).

2.4. Data Collection. To generate the data set used in this study, pretested structured questionnaires were used to collect data by trained data collectors. Explanatory variables were selected after conducting a detailed literature review from related articles to collect data on the sociodemographic, nutritional, and health-related variables [16-19]. The questionnaires were translated into the local language (Amharic) for easy understanding by the respondents. Each student was interviewed to obtain information on sociodemographic, nutritional, and health-related characteristics of the adolescents' family.

Anthropometric data were collected by trained data collectors who were health extension workers. And the overall activity was coordinated by the investigator. The age of the adolescents was derived from the school register. Height and weight were measured using a stadiometer and Seca Digital Scale (Seca, Germany), respectively. The weight was recorded to the nearest $0.1 \mathrm{~kg}$. It was calibrated against the known weight regularly. Before the real anthropometric data collection, a standardization exercise was performed during the training to capture technical error of 


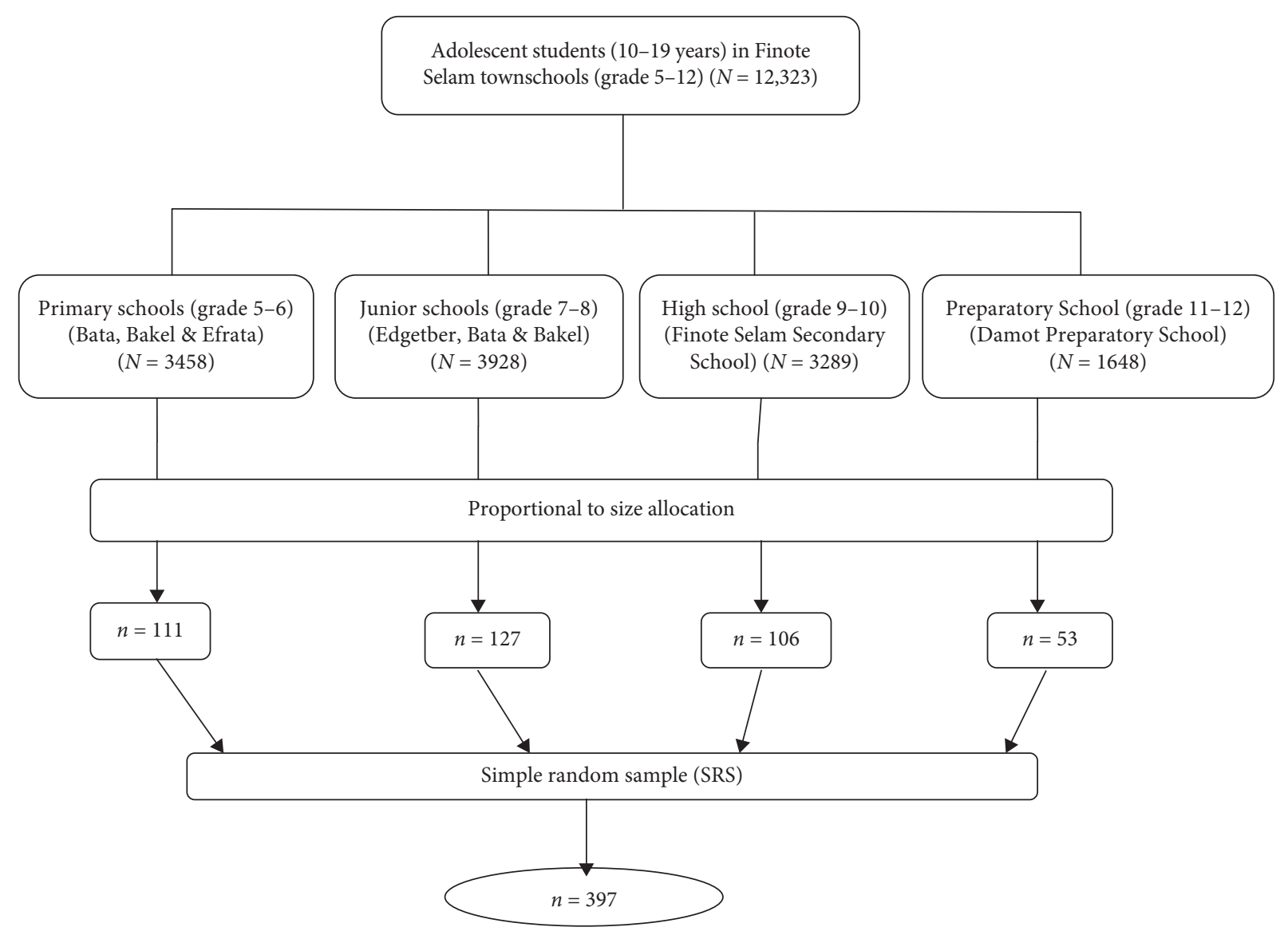

Figure 1: Schematic presentation of sampling procedures.

measurement. During the procedure, the subjects wore light clothes and took off their shoes. Height was measured in $\mathrm{cm}$ using a portable stadiometer. All adolescents were measured against the wall without foot wear and with heels together and their heads position and eyes looking straight ahead (Frankfurt plane) so that the line of sight was perpendicular to the body. The height was recorded to the nearest $0.1 \mathrm{~cm}$. The same measurer was employed for a given anthropometric measurement to avoid variability.

2.5. Data Quality Control and Management. To ensure the reliability and validity of the study, training was given for the data collectors, the data collection was done by two health extension workers, and close follow-up was done by the investigator during data collection. The Amharic version of the questionnaire was tested on $5 \%$ of the samples at the Selamamba Primary School, who have similar characteristics with the study participant but did not participate in the study. The data collectors and investigator were participated on pretesting and standardization of the questionnaires. Problems highlighted during the preliminary study were corrected before the start of the actual survey. Each question was properly coded; continuous supervision was performed during the pretest and data collection period by the investigator. Completeness and consistency of recording on the questionnaire sheets were evaluated by the investigator at the end of each working day so that correction measures were taken for the next time.

2.6. Data Analyses. Sociodemographic, anthropometric, nutrition, and health-related data were entered into Epi Info version 7 and checked for completeness and consistency, followed by data cleaning and editing on Epi Info. Then, the data were analyzed by using SPSS (Statistical Package for Social Sciences), version 20 software. WHO AnthroPlus software was used for assessing growth of the adolescents [20]. Descriptive statistics using frequencies and proportions was used to present the study results. For anthropometric data analysis, if the BMI-for-age $Z$-score is below minus two standard deviations ( -2 SDs) from the median of the reference population, then the child is thin. Odds ratio with 95\% confidence interval was used for checking the strength of associations between the outcome variable (thinness) and independent variables. Bivariate logistic regression was performed, and the variable with $p$ value less than 0.25 was transported into multivariable binary logistic regression analysis to identify the determinant of malnutrition of under-five children. Finally, variables with $p$ values $<0.05$ in the multivariable logistic regression model were taken as statistically significant [21]. 


\section{Results}

3.1. Sociodemographic Characteristics of Study Participants and Their Family. From a total of 397 adolescent students who were selected as a sample, with $100 \%$ response rate, all study participants were involved in this study. Among these, $47(11.8 \%)$ were early adolescents, 151 (38.0\%) were midadolescents, and 199 (50.1\%) were late adolescents. From the participants, $108(27.2 \%)$ were from primary schools, 132 (32.2\%) were from junior schools, while 116 (29.2\%) were from the high school, and others $41(10.3 \%)$ were attending the preparatory school. Of the total participants, $195(49.1 \%)$ were from urban areas, whereas 202 (50.9\%) were from rural areas (Table 1).

3.2. Nutrition and Health-Related Characteristics of School Adolescents. Most of the adolescents, 278 (70.0\%), were consuming meals three and above times per day, whereas $119(30.0 \%)$ of adolescents were consuming meals two times per day. Among the respondents, 33.0\% were reported having illness in the last one month. Among the respondents, 288 (72.5\%) had home gardens. Vegetables $(46.1 \%)$ and fruits $(51.4 \%)$ were consumed daily (Table 2 ).

3.3. Anthropometric Results. The minimum and maximum heights of study subjects were $127.50 \mathrm{~cm}$ and $186.70 \mathrm{~cm}$, respectively. The mean $\pm \mathrm{SD}$ overall height of the participants was $158 \pm 10.67 \mathrm{~cm}$. Similarly, the minimum and maximum weights of study participants were $20.5 \mathrm{~kg}$ and $68 \mathrm{~kg}$, respectively. The mean \pm SD overall weight of the participants was $45.99 \pm 10.09 \mathrm{~kg}$. The mean heights of boys and girls were $158.99 \pm 12.24 \mathrm{~cm}$ and $156.31 \pm 6.94 \mathrm{~cm}$, respectively. Similarly, the mean weights of boy and girl adolescents were $45.1 \pm 10.97 \mathrm{~kg}$ and $47.53 \pm 8.17 \mathrm{~kg}$, respectively. The mean age of the study participants was 15.54 years $(15.54 \pm 2.41 \mathrm{SD})$.

Prevalence of thinness: the overall prevalence of thinness among adolescent students at Finote Selam Town was $14.9 \%$.

The mean $Z$-score of BMI-for-age of all adolescents was -1.13 which revealed the distribution of BAZ (Figure 2).

The mean $Z$-scores of BMI-for-age among boys and girls were -1.29 and -0.51 that showed the distribution of BAZ, respectively (Figure 3 ).

3.4. Factors Associated with Thinness. Exploring determinants associated with thinness is important to take nutritional intervention action in the study area. Results of the multivariable binary logistic regression model showed that the age, sex, family monthly income, and sources of drinking water were significantly associated with thinness. The odds of thinness were 4.81 times higher among adolescent students in the early adolescent stage as compared to adolescent students in the late adolescent stage $(\mathrm{AOR}=4.81 ; 95 \% \mathrm{CI}$ : $1.23,18.51)$. Male adolescent students had 2.13 times higher odds of thinness $(\mathrm{AOR}=2.13 ; 95 \% \mathrm{CI}: 1.60,3.40)$ compared to female adolescent students. The students who came from
TABle 1: Sociodemographic-related characteristics of adolescent students at Finote Selam Town, Ethiopia, 2018.

\begin{tabular}{|c|c|c|}
\hline Variables & Frequency & Percentage \\
\hline \multicolumn{3}{|l|}{ Age group } \\
\hline Early adolescent (10-13) & 47 & 11.8 \\
\hline Midadolescent (14-16) & 151 & 38.0 \\
\hline Late adolescent (17-19) & 199 & 50.1 \\
\hline \multicolumn{3}{|l|}{ Sex } \\
\hline Female & 148 & 37.3 \\
\hline Male & 249 & 62.7 \\
\hline \multicolumn{3}{|l|}{ Grade } \\
\hline Grade 5-6 & 108 & 27.2 \\
\hline Grade $7-8$ & 132 & 33.2 \\
\hline Grade $9-10$ & 116 & 29.2 \\
\hline Grade $11-12$ & 41 & 10.3 \\
\hline \multicolumn{3}{|l|}{ Religion } \\
\hline Muslim & 22 & 5.5 \\
\hline Orthodox & 375 & 94.5 \\
\hline \multicolumn{3}{|l|}{ Place of residence } \\
\hline Urban & 195 & 49.1 \\
\hline Rural & 202 & 50.9 \\
\hline \multicolumn{3}{|l|}{ Father's education } \\
\hline Illiterate & 95 & 23.8 \\
\hline Read and write & 101 & 25.4 \\
\hline Primary school (1-8) & 41 & 10.3 \\
\hline Secondary school (9-12) & 92 & 23.2 \\
\hline College and above & 68 & 17.1 \\
\hline \multicolumn{3}{|l|}{ Mother's education } \\
\hline Illiterate & 102 & 25.7 \\
\hline Read and write & 109 & 27.5 \\
\hline Primary school (1-8) & 34 & 8.6 \\
\hline Secondary school (9-12) & 89 & 22.4 \\
\hline College and above & 63 & 15.9 \\
\hline \multicolumn{3}{|l|}{ Father's occupation } \\
\hline Daily laborer & 57 & 14.4 \\
\hline Farmer & 119 & 30.0 \\
\hline Merchant & 85 & 21.4 \\
\hline Government/nongovernment employee & 136 & 34.3 \\
\hline \multicolumn{3}{|l|}{ Mother's occupation } \\
\hline Daily laborer & 5 & 1.3 \\
\hline Housewife & 86 & 21.7 \\
\hline Merchant & 119 & 30.0 \\
\hline Farmer & 107 & 27.0 \\
\hline Government/nongovernment employee & 80 & 20.2 \\
\hline \multicolumn{3}{|l|}{ Family size } \\
\hline$<5$ & 173 & 43.6 \\
\hline$\geq 5$ & 224 & 56.4 \\
\hline \multicolumn{3}{|l|}{ Monthly family income } \\
\hline$<1000$ birr & 77 & 19.3 \\
\hline $1000-2000$ birr & 107 & 27.0 \\
\hline$>2000$ birr & 213 & 53.7 \\
\hline \multicolumn{3}{|l|}{ Source of drinking water } \\
\hline Spring water & 82 & 20.7 \\
\hline Well water & 106 & 26.7 \\
\hline Public tap water & 26 & 6.5 \\
\hline Tap water & 183 & 46.1 \\
\hline \multicolumn{3}{|l|}{ Presence of functional latrine } \\
\hline Yes & 257 & 64.7 \\
\hline No & 140 & 35.3 \\
\hline
\end{tabular}


TABLE 2: Nutrition and health-related characteristics of school adolescents at Finote Selam Town, Ethiopia, 2018.

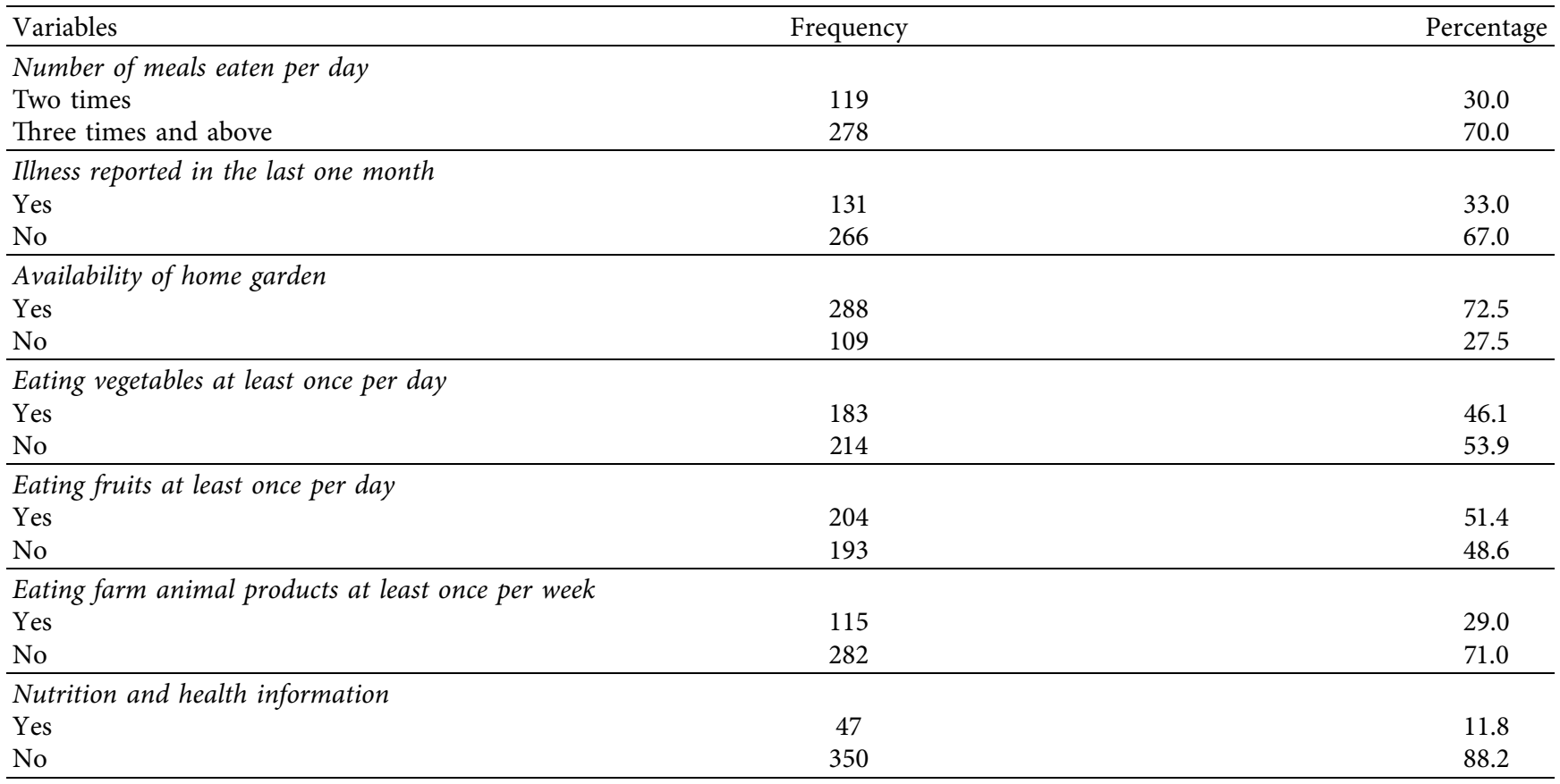

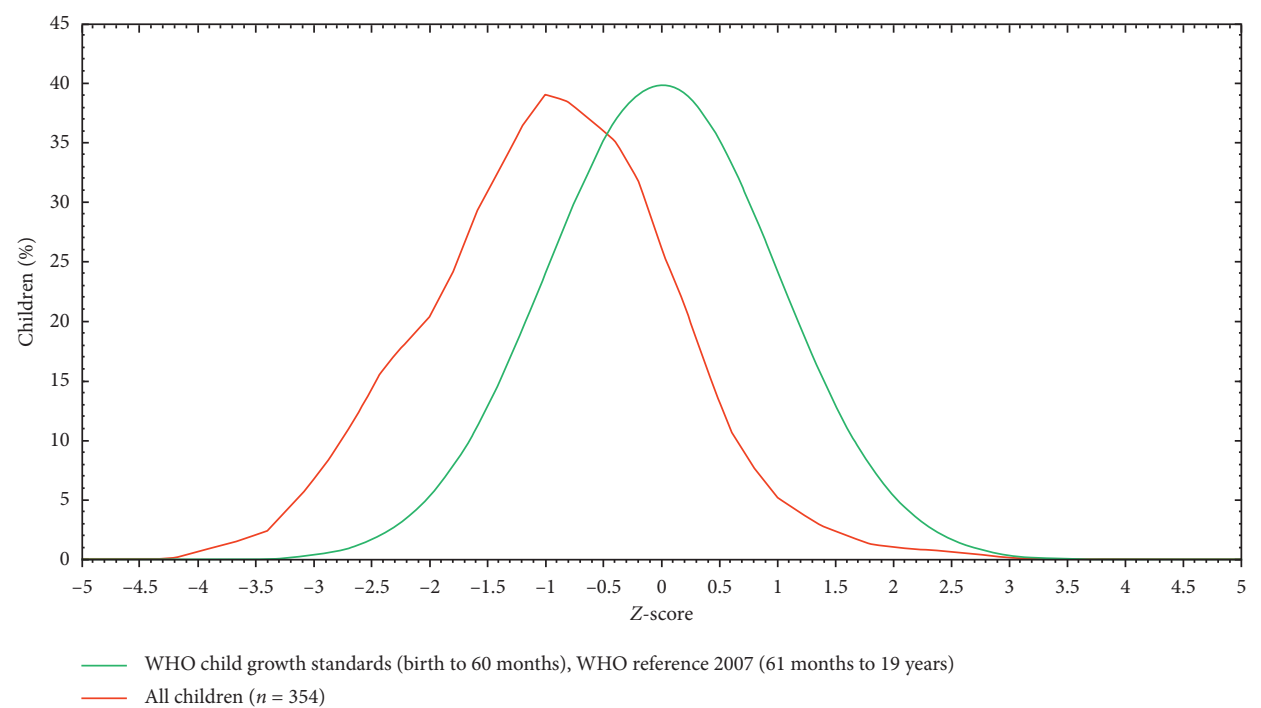

Figure 2: BMI-for-age $Z$-score of adolescent students in Finote Selam Town, Ethiopia.

rural area were $2.16(\mathrm{AOR}=2.61 ; 95 \% \mathrm{CI}: 0.96,4.87)$ times more likely to be thin compare to those who came from urban area. The students from less than 1000 and 1000-2000 birr family monthly income were $6.54(\mathrm{AOR}=6.54 ; 95 \% \mathrm{CI}$ : $3.82,14.89)$ and $3.47(\mathrm{AOR}=3.47 ; 95 \% \mathrm{CI}: 1.15,7.45)$ times more likely to be thin compared to greater than 2000 birr family monthly income, respectively. Students from households that used well water supply as main source of water supply were 3.82 times more likely to be at risk of being thin than students from households that used tap water supply for human consumption $(\mathrm{AOR}=3.82 ; 95 \% \mathrm{CI}$ : $1.46,10.04$ ) (Table 3).

\section{Discussion}

In this study, the prevalence of thinness and associated factors in Finote Selam Town, Northwest Ethiopia, was assessed. The prevalence of thinness was $14.9 \%$, and this finding was lower than the studies in Mekelle City $(37.8 \%)$ [15], Ambo City (27.5\%) [22], Wukro District (26.1\%) [16], and Seychelles (27.7\%) [23]. Another study in Ethiopia, in Jimma Zone, has reported a much higher level $(80.8 \%)$ of thinness prevalence among adolescents [24]. The prevalence of thinness of this study was higher than studies done in Addis Ababa (6.2\%) (13\%) [25]. This divergence might be 


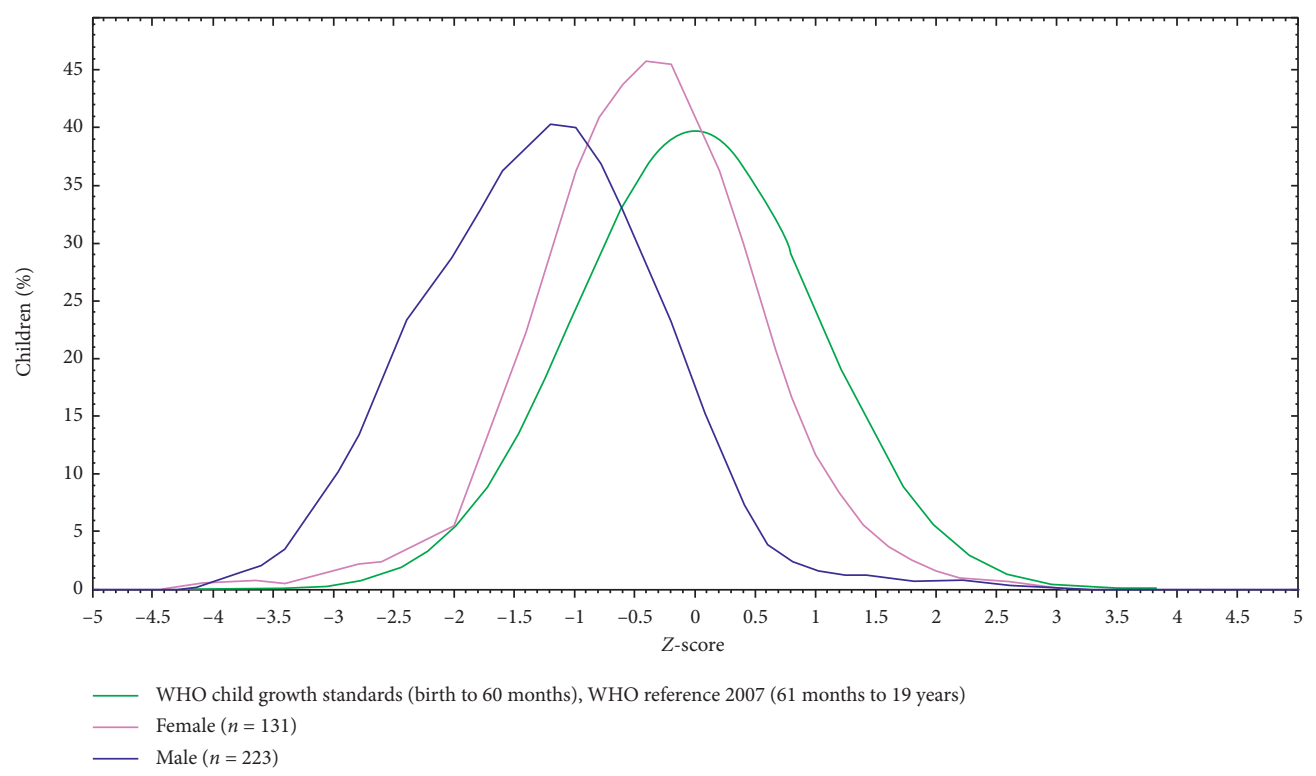

Figure 3: BMI-for-age $Z$-score of by sex of adolescent students in Finote Selam Town, Ethiopia.

due to the difference in socioeconomic background, dietary habit, and type of meals among the cities. Findings in other African countries include Burkina Faso (13.7\%) [26], Asembo and Mumias, Kenya (15.6\%) [27], Tunisia (13\%) [28], and Tamale Metropolis district, Ghana (10\%) [29]. The variation might be due to socioeconomic background, geographical characteristics of study area, cultural difference in dietary habit, and care practices.

The odds of thinness were 4.81 times higher among adolescent students in the early adolescent stage as compared to adolescent students in the late adolescent stage. This finding was in agreement with findings from Adwa Town, Northen Ethiopia, [17] and in Community-Based Nutrition implementing districts, Amhara Region, Ethiopia [30]. This might be due to as age increases, adolescents might access food easily by themselves; on the other hand, as age increases, adolescents become more matured. Male adolescent students had 2.13 times higher odds of thinness compared to female adolescent students. This study was in line with the studies conducted in Mekelle City, Northern Ethiopia [15], Jimma Zone, Southwest Ethiopia [24], and Wukro, Northern Ethiopia [16] which confirmed that males were more affected in thinness than girls. This might be due to variation of maturation time in boys and girls, for which girls reached maturation earlier than boys.

The students who came from rural area were 2.16 times more likely to be thin compared to those who came from urban area. This finding is in agreement with other previously conducted studies $[12,16]$. The variation might be due to food preference, food consumption pattern, and inequalities in dietary diversity between urban and rural areas. The risk of being thin among school adolescents whose mothers did not attend education was 1.78 times more compared to school adolescents whose mother attended college and above education. This finding is consistent with the study that conducted in Adama City, Central Ethiopia
[31]. The risk of being thin among school adolescents whose mothers attended primary school (1-8) and secondary school (9-12) education was 1.29 and 1.15 (AOR $=1.15 ; 95 \%$ CI: $0.66,1.97)$ times more compared to students whose mothers attended college and above education, respectively. This finding is in line with the study that conducted in Adama City, Central Ethiopia [32]. This is due to the fact that if the level of education of the mother is low, her decision-making and her contribution to the total family income will be low. This places the family at risk of not meeting their needs including nutritional needs.

The odds of being thin were 1.90 times higher among school adolescents who lived in household members of $\geq 5$ than school adolescents who had lived in household members $<5$. This finding was in line with the study that conducted in Adwa Town, North Ethiopia [12]. This might be due to sharing of the available food for the large household members, causing inadequate consumption of food, leading to be thin. The students who did not eat vegetables and fruits at least once per day were 1.30 and 1.23 times more likely to be thin compared to those who ate once per day. This finding is in agreement with the study that conducted in Adwa Town, North Ethiopia [12]. This is might be due to the fact that consuming insufficient vegetables and fruits are leading to poor nutritional status.

The students from less than 1000 and 1000-2000 birr family monthly income were 6.54 and 3.47 times more likely to be thinness compared to greater than 2000 birr family monthly income, respectively. This might be due to the better income level of the family would enhance the nutrition status of the adolescents. Students from households that used well water supply as main source of water supply were 3.82 times more likely to be at risk of being thinness than students from households that used tap water supply for human consumption. This finding was in line with findings from Adwa Town, Northen Ethiopia [17]. This 
TABLE 3: Bivariate and multivariable logistic regression of factors associated with thinness among adolescent school students, Finote Selam Town, Ethiopia, 2018.

\begin{tabular}{|c|c|c|c|c|}
\hline \multirow{2}{*}{ Variables } & \multicolumn{2}{|c|}{ Thinness } & \multirow{2}{*}{ COR (95\% CI) } & \multirow{2}{*}{ AOR (95\% CI) } \\
\hline & Yes & No & & \\
\hline \multicolumn{5}{|l|}{ Age Group } \\
\hline Early adolescent (10-13) & $17(36.2 \%)$ & $30(63.8 \%)$ & $5.14(2.39,11.08)^{*}$ & $4.81(1.23,18.51)^{*}$ \\
\hline Midadolescent (14-16) & $24(15.9 \%)$ & $127(84.1 \%)$ & $1.90(0.99,3.64)$ & $1.68(0.57,4.93)$ \\
\hline Late adolescent (17-19) & $18(9.0 \%)$ & $181(91.0 \%)$ & 1 & 1 \\
\hline \multicolumn{5}{|l|}{$\operatorname{Sex}$} \\
\hline Female & $4(2.7 \%)$ & $144(97.3 \%)$ & 1 & 1 \\
\hline Male & $55(22.1 \%)$ & $194(77.9 \%)$ & $2.68(1.88,3.84)$ & $2.13(1.60,3.40)^{*}$ \\
\hline \multicolumn{5}{|l|}{ Grade } \\
\hline Grade 5-6 & $23(21.3 \%)$ & $85(78.7 \%)$ & $2.57(0.91,7.24)$ & $1.77(0.40,7.87)$ \\
\hline Grade 7-8 & $22(16.7 \%)$ & $110(83.3 \%)$ & $2.08(0.74,5.86)$ & $1.33(0.22,8.19)$ \\
\hline Grade 9-10 & $10(8.6 \%)$ & $106(91.4 \%)$ & $1.01(0.32,3.15)$ & $1.06(0.20,5.58)$ \\
\hline Grade $11-12$ & $4(9.8 \%)$ & $37(90.2 \%)$ & 1 & 1 \\
\hline \multicolumn{5}{|l|}{ Religion } \\
\hline Muslim & $1(4.5 \%)$ & $21(95.5 \%)$ & 1 & 1 \\
\hline Orthodox & $58(15.5 \%)$ & $317(84.5 \%)$ & $3.82(0.50,29.18)$ & $3.90(0.19,81.94)$ \\
\hline \multicolumn{5}{|l|}{ Place of residence } \\
\hline Urban & $18(9.2 \%)$ & $177(90.8 \%)$ & 1 & 1 \\
\hline Rural & $41(20.3 \%)$ & $161(79.7 \%)$ & $2.44(1.35,4.40)^{*}$ & $2.16(0.96,4.87)$ \\
\hline \multicolumn{5}{|l|}{ Father's education } \\
\hline Illiterate & $15(15.8 \%)$ & $80(84.2 \%)$ & $2.79(0.92,8.45)$ & $4.06(0.23,71.76)$ \\
\hline Read and write & $17(16.8 \%)$ & $84(83.2 \%)$ & $1.97(0.71,5.43)$ & $2.73(0.31,24,29)$ \\
\hline Primary school (1-8) & $10(24.4 \%)$ & $31(75.6 \%)$ & $1.96(0.73,5.32)$ & $2.36(0.26,21.41)$ \\
\hline Secondary school (9-12) & $11(12.0 \%)$ & $81(88.0 \%)$ & $1.44(0.51,4.10)$ & $0.80(0.5,12.90)$ \\
\hline College and above & $6(8.8 \%)$ & $62(91.2 \%)$ & 1 & 1 \\
\hline \multicolumn{5}{|l|}{ Mother's education } \\
\hline Illiterate & $17(16.7 \%)$ & $85(83.3 \%)$ & $2.38(0.77,7.39)$ & $1.78(0.86,3.65)$ \\
\hline Read and write & $16(14.7 \%)$ & $93(85.3 \%)$ & $1.86(0.68,5.07)$ & $1.40(0.83,2.34)$ \\
\hline Primary school (1-8) & $9(26.5 \%)$ & $25(73.5 \%)$ & $1.50(0.55,4.09)$ & $1.29(0.61,2.71)$ \\
\hline Secondary school (9-12) & $11(12.4 \%)$ & $78(87.6 \%)$ & $1.33(0.47,3.81)$ & $1.15(0.66,1.97)$ \\
\hline College and above & $6(9.5 \%)$ & $57(90.5 \%)$ & 1 & 1 \\
\hline \multicolumn{5}{|l|}{ Father's occupation } \\
\hline Daily laborer & $8(14.0 \%)$ & $49(86.0 \%)$ & $1.20(0.47,3.07)$ & $1.1(0.55,21)$ \\
\hline Farmer & $26(21.8 \%)$ & $93(78.2 \%)$ & $2.27(1.12,4.61)^{*}$ & $1.55(0.45,5.29)$ \\
\hline Merchant & $11(12.9 \%)$ & $74(87.1 \%)$ & $1.18(0.50,2.75 \%)$ & $1.52(0.55,4.26)$ \\
\hline Government/nongovernment employee & $14(10.3 \%)$ & $122(89.7 \%)$ & 1 & 1 \\
\hline \multicolumn{5}{|l|}{ Mother's occupation } \\
\hline Daily laborer & $1(20.0 \%)$ & $4(80.0 \%)$ & $1.86(0.19,18.55)$ & $2.10(0.11,38.74)$ \\
\hline Farmer & $21(24.4 \%)$ & $65(75.6 \%)$ & $2.74(1.16,6.46)^{*}$ & $2.16(0.62,7.51)$ \\
\hline Housewife & $15(12.6 \%)$ & $104(87.4 \%)$ & $1.33(0.55,3.23)$ & $2.46(0.58,10.47)$ \\
\hline Merchant & $13(12.1 \%)$ & $94(87.9 \%)$ & $1.24(0.51,3.04)$ & $1.52(0.43,5.36)$ \\
\hline Government/nongovernment employee & $9(11.2 \%)$ & $71(88.8 \%)$ & 1 & 1 \\
\hline \multicolumn{5}{|l|}{ Family size } \\
\hline$<5$ & $17(9.8 \%)$ & $156(90.2 \%)$ & 1 & 1 \\
\hline$\geq 5$ & $42(18.8 \%)$ & $182(81.2 \%)$ & $2.43(1.32,4.45)^{*}$ & $1.90(0.80,4.51)$ \\
\hline \multicolumn{5}{|l|}{ Family monthly income } \\
\hline$<1000$ & $29(37.7 \%)$ & $48(62.3 \%)$ & $6.10(3.09,12.04)^{*}$ & $11.54(3.82,34.89)^{*}$ \\
\hline $1000-2000$ & $14(13.1 \%)$ & $93(86.9 \%)$ & $1.71(0.80,3.64)$ & $3.47(1.15,10.45)^{*}$ \\
\hline$>2000$ & $16(7.5 \%)$ & $197(92.5 \%)$ & 1 & 1 \\
\hline \multicolumn{5}{|l|}{ Source of drinking water } \\
\hline Well water & $39(21.3 \%)$ & $144(78.7 \%)$ & $4.53(1.71,11.98)$ & $3.82(1.46,10.04)^{*}$ \\
\hline Spring water & $13(12.3 \%)$ & $93(87.7 \%)$ & $3.37(0.88,12.89)$ & $2.56(0.87,7.56)$ \\
\hline Public tap water & $2(7.7 \%)$ & $24(92.3 \%)$ & $1.88(0.23,15.49)$ & $1.46(0.26,8.09)$ \\
\hline Tap water & $5(6.1 \%)$ & $77(93.9 \%)$ & 1 & 1 \\
\hline \multicolumn{5}{|l|}{ Presence of functional latrine } \\
\hline Yes & $38(14.8 \%)$ & $219(85.2 \%)$ & 1 & 1 \\
\hline
\end{tabular}


TABLE 3: Continued.

\begin{tabular}{|c|c|c|c|c|}
\hline \multirow{2}{*}{ Variables } & \multicolumn{2}{|c|}{ Thinness } & \multirow{2}{*}{ COR $(95 \% \mathrm{CI})$} & \multirow{2}{*}{$\operatorname{AOR}(95 \% \mathrm{CI})$} \\
\hline & Yes & No & & \\
\hline No & $21(15.0 \%)$ & $119(85.5 \%)$ & $1.08(0.49,2.38)$ & $1.05(0.59,1.87)$ \\
\hline \multicolumn{5}{|c|}{ Number of meals eaten per day } \\
\hline Two times & $19(16.0 \%)$ & $100(84.0 \%)$ & $1.17(0.64,2.13)$ & $1.01(0.53,1.91)$ \\
\hline Three times and above & $40(14.4 \%)$ & $238(85.6 \%)$ & 1 & 1 \\
\hline \multicolumn{5}{|c|}{ Illness reported in the last one month } \\
\hline Yes & $19(14.5 \%)$ & $112(85.5 \%)$ & $1.06(0.57,1.96)$ & $1.03(0.57,1.87)$ \\
\hline No & $40(15.0 \%)$ & $226(85.0 \%)$ & 1 & 1 \\
\hline \multicolumn{5}{|c|}{ Availability of home garden } \\
\hline Yes & $50(17.4 \%)$ & $238(82.6 \%)$ & 1 & 1 \\
\hline No & $9(8.3 \%)$ & $100(91.7 \%)$ & $1.60(1.01,2.54)$ & $1.15(0.66,1.99)$ \\
\hline \multicolumn{5}{|c|}{ Eating vegetables at least once per day } \\
\hline Yes & $23(12.6 \%)$ & $160(87.4 \%)$ & 1 & 1 \\
\hline No & $36(16.8 \%)$ & $178(83.2 \%)$ & $1.35(0.76,2.60)$ & $1.30(0.72,2.36)$ \\
\hline \multicolumn{5}{|c|}{ Eating fruits at least once per day } \\
\hline Yes & $26(12.7 \%)$ & $178(87.3 \%)$ & 1 & 1 \\
\hline No & $33(17.1 \%)$ & $160(82.9 \%)$ & $1.33(0.76,2.31)$ & $1.23(0.69,2.18)$ \\
\hline \multicolumn{5}{|c|}{ Eating farm animal products at least once per week } \\
\hline Yes & $14(12.2 \%)$ & $101(87.8 \%)$ & 1 & 1 \\
\hline No & $45(16.0 \%)$ & $237(84.0 \%)$ & $1.20(0.62,2.29)$ & $1.19(0.61,2.34)$ \\
\hline \multicolumn{5}{|c|}{ Nutrition and health information } \\
\hline Yes & $6(12.8 \%)$ & $41(87.2 \%)$ & 1 & 1 \\
\hline No & $53(15.1 \%)$ & $297(84.9 \%)$ & $1.15(0.49,2.71)$ & $1.08(0.43,2.69)$ \\
\hline
\end{tabular}

might be due to the fact that impure water is a vehicle for intestinal parasites which leads to loss of appetite, leading to poor nutritional status; this might also be due to repeated infection causing depressed immunity and making the severity and duration of disease more severe, contributing to poor nutritional status of the adolescents.

\section{Conclusions}

The prevalence of thinness was high in the study area. Consistent with this result, the mean $Z$-scores of BMI-forage were higher in boys than girls. Age, sex, family monthly income, and sources of drinking water were significantly associated with thinness among the respondents. Based on the finding, there should be collaboration among health sectors and education sectors of the town to address school adolescents under nutrition problems of the town.

\section{Abbreviations}

AOR: Adjusted odds ratio

CM: Centimeter

COR: Crude odds ratio

CSA: Central statistics agency

CV: Confidence interval

EDHS: Ethiopian demography and health survey

SD: $\quad$ Standard deviation

SPSS: Statistical Package for Social Sciences

UN: United Nations

WHO: World Health Organization.

\section{Data Availability}

All data in this study are included in the figures, tables, and statements.

\section{Ethical Approval}

The study was approved by the University Ethical Committee of Faculty of Chemical and Food Engineering, Bahir Dar University (protocol no. 12/2010). Supportive letters were obtained from the Amhara Public Health Institute which wrote a letter to the West Gojjam Zone Health Office, and then the West Gojjam Zone Health Office wrote a letter to the Finote Selam Town Administration Health Office. Finally, Finote Selam Town Administration Health Office wrote a letter to target schools.

\section{Consent}

Written informed consent was obtained from the adolescents' parents or legal guardians, after clearly explaining the research objectives.

\section{Conflicts of Interest}

The authors declare that they have no conflicts of interest.

\section{Authors' Contributions}

Damitie Kebede Mengesha has designed the study and involved in data collection, supervision, and data processing. Damitie Kebede Mengesha has cleaned and analyzed the data as well as interpreted the results and drafted the 
manuscript. Reddy P. C. J. Prasad and Degnet Teferi Asres participated in cleaning, analyzing, and interpreting the data. Damitie Kebede Mengesha, Reddy P. C. J. Prasad, and Degnet Teferi Asres critically reviewed the manuscript. All authors read and approved the final manuscript.

\section{Acknowledgments}

The authors are thankful to adolescent students, school directors, health officers, data collectors, and supervisors of this study.

\section{References}

[1] WHO, Adolescent Nutrition a Neglected Dimension, WHO, Geneva, Switzerland, 2013.

[2] C. Namrata and C. Archana, "A comparative study of nutritional intake in adolescentgirls," 2013.

[3] M. R. Khan and F. Ahmed, "Physical Status, nutrient intake and dietary pattern of adolescent female factory workers in Urban Bangladesh," Asia Pacific Journal of Clinical Nutrition, vol. 14, no. 1, pp. 19-26, 2005.

[4] S. Sally, "California state, 4-H center for youth development, the biology of adolescence," 2013.

[5] UNICEF, Adolescence an Age of Opportunity the State of the World's Children, United Nations Press, New York, NY, USA, 2011.

[6] J. E. Brown and J. Stang, Nutrition through Life the Cycle, Wadsworth Cengage Learning, Belmont, CA, USA, 4th edition, 2011.

[7] M. D. Gupta, R. Engelman, J. Levy, G. Luchsinger, T. Merrick, and J. E. Rosen, The Power of 1.8 Million Adolescent, Youth and the Transformation of the Future, United Nations Population Fund, New york, NY, USA, 2014.

[8] M. R. Burt, "Why should we invest in adolescents?" in Proceedongs of the Paper Prepared for the Conference on Comprehensive Health of Adolescents and Youth in Latin America and the Caribbean, Washington, DC, USA, 2013.

[9] CSA, Centeral Statistics Agency of Ethiopia, Addis Ababa, 2007.

[10] K. Teji, Y. Dessie, T. Assebe et al., "Anaemia and nutritional status of adolescent girls in Babile district, Eastern Ethiopia," Pan African Medical Journal, vol. 24, p. 62, 2016.

[11] T. Wolde, W. A. D. Mekonnin, F. Yitayin et al., "Nutritional status of adolescent girls living in southwest of Ethiopia," Food Science and Human Wellness, vol. 34, pp. 58-64, 2014.

[12] T. Gebregyorgis, T. Tadesse, and A. Atenafu, "Prevalence of thinness and stunting and associated factors among adolescent schoolgirls in Adwa Town, North Ethiopia," International Journal of Food Science, vol. 2016, Article ID 8323982, 8 pages, 2016.

[13] Y. Yemaneh, A. Girma, W. Nigussie et al., "Undernutrition and its associated factors among adolescent girls in the rural community of Aseko district, Eastern Arsi Zone, Oromia region, Eastern Ethiopia, 2017," International Journal of Clinical Obstetrics and Gynaecology, vol. 1, no. 2, pp. 17-26, 2017.

[14] G. Arage, M. Assefa, and T. Worku, "Socio-demographic and economic factors are associated with nutritional status of adolescent school girls in Lay Guyint Woreda, Northwest Ethiopia," SAGE Open Medicine, vol. 7, 2019.

[15] H. Gebremariam, S. Omer, and H. Assefa, "Assessment of nutritional status and associated factors among school going adolescents of Mekelle City, Northern Ethiopia," International Journal of Nutrition and Food Sciences, vol. 4, no. 1, pp. 118-124, 2015.

[16] Y. A. Melaku, G. A. Zello, T. K. Gill, R. J. Adams, and Z. Shi, "Prevalence and factors associated with stunting and thinness among adolescent students in Northern Ethiopia: a comparison to World Health Organization standards," Archives of Public Health, vol. 4, no. 1, 2015.

[17] FTEO. Finoteselam Education Office; 2017.

[18] S. M. Birru, A. Tariku, and A. K. Belew, "Improved dietary diversity of school adolescent girls in the context of urban Northwest Ethiopia," Italian Journal of Pediatrics, vol. 44, p. 48, 2018.

[19] A. Y. Mohammed and T. B. Tefera, "Nutritional status and associated risk factors among adolescents girls in Agarfa High School, Bale Zone, Oromia Region, South East Ethiopia," International Journal of Nutrition and Food Sciences, vol. 4, no. 4, pp. 445-152, 2015.

[20] WHO, AnthroPlus for Personal Computers Manual: Software for Assessing Growth of the World's Children and Adolescents, WHO, Geneva, Switzerland, 2009.

[21] D. W. Hosmer and S. Lemeshow, Applied Logistic Regression, John Wiley \& Sons, Inc., New York, NY, USA, 2nd edition, 2000.

[22] Z. Alebachew, Prevalence of Childhood and Adolescent Overweight and Obesity Among Elementary School Students, Addis Ababa University, Addis Ababa, Ethiopia, 2010.

[23] P. Bovet, N. Kizirian, G. Madeleine, M. Blössner, and A. Chiolero, "Prevalence of thinness in children and adolescents in the Seychelles: comparison of two international growth references," Nutrition Journal, vol. 10, p. 65, 2011.

[24] H. Assefa, T. Belachew, and L. Negash, "Socioeconomic factors associated with underweight and stunting among adolescents of Jimma Zone, South West Ethiopia," ISRN Public Health, vol. 2013, Article ID 238546, 7 pages, 2013.

[25] M. Yetubie, "Anthropometric assessment of adolescent malnutrition in elementary and secondary schools of ambo," Thesis, Addis Ababa University, Addis Ababa, Ethiopia, 2012.

[26] C. Daboné, H. F. Delisle, and O. Receveur, "Poor nutritional status of schoolchildren in urban and peri-urban areas of Ouagadougou (Burkina Faso)," Nutrition Journal, vol. 10, p. 34, 2011.

[27] T. Leenstra, L. T. Petersen, S. K. Kariuki, A. J. Oloo, P. A. Kager, and F. O. t. Kuile, "Prevalence and severity of malnutrition and age at menarche; cross-sectional studies in adolescent schoolgirls in western Kenya," European Journal of Clinical Nutrition, vol. 59, no. 1, pp. 41-48, 2005.

[28] H. Aounallah-Skhiri, H. B. Romdhane, P. Traissac et al., "Nutritional status of Tunisian adolescents: associated gender, environmental and socio-economic factors," Public Health Nutrition, vol. 11, no. 12, pp. 1306-1317, 2008.

[29] A. Abiba, A. N. K. Grace, and K. C. Kubreziga, "Effects of dietary patterns on the nutritional status of upper primary school children in Tamale metropolis," Pakistan Journal of Nutrition, vol. 11, no. 7, pp. 591-609, 2012.

[30] M. M. Wassie, A. A. Gete, M. E. Yesuf, G. D. Alene, A. Belay, and T. Moges, "Predictors of nutritional status of Ethiopian adolescent girls: a community based cross sectional study," BMC Nutrition, vol. 1, no. 1, p. 20, 2015.

[31] A. Kassa Tekile, A. Abate Woya, and G. W. Basha, "Prevalence of malnutrition and associated factors among under-five children in Ethiopia: evidence from the 2016 Ethiopia Demographic and Health Survey," BMC Research Notes, vol. 12, no. 1, 2019.

[32] R. Kt, A. M, and T. Wakayo, "Nutritional status and its associated factors among school adolescent girls in Adama City, Central Ethiopia," Journal of Nutrition \& Food Sciences, vol. 6, no. 3, p. 493, 2016. 